\title{
PRIMEIRO REGISTRO DE Oligonychus yothersi (McGREGOR) (ACARI: TETRANYCHIDAE) EM Eucalyptus grandis Hill ex Maiden NO BRASIL ${ }^{1}$
}

Fabrício Fagundes Pereira ${ }^{2}$, Norivaldo dos Anjos ${ }^{2}$, Roosevelt de Paula Almado ${ }^{2}$ e Luís Antônio Lopes Rodrigues ${ }^{2}$

\begin{abstract}
RESUMO - Relata-se a infestação de um ácaro-vermelho em mudas clonais de Eucalyptus grandis Hill ex Maiden, mantidas em casa de vegetação no município de Martinho Campos, Minas Gerais. O ácaro foi observado na parte superior das folhas que exibiam sinais de sucção de seiva e bronzeamento. Essas injúrias causaram desenvolvimento anormal e morte de plantas. O ácaro foi identificado como Oligonychus yothersi (McGregor) (Acari: Tetranychidae), e isso representa o primeiro registro dessa espécie em mudas clonais de E. grandis no Brasil.
\end{abstract}

Palavras-chave: Ácaro-vermelho, mudas clonais e eucalipto.

\section{FIRST RECORD OF Oligonychus yothersi (McGREGOR) (ACARI: TETRANYCHIDAE) ON Eucalyptus grandis Hill ex Maiden IN BRAZIL}

\begin{abstract}
An infestation of the red spider mite was reported in clone seedlings of Eucalyptus grandis Hill ex Maiden under greenhouse conditions, in the municipality of Martinho Campos, Minas Gerais State. The spider mite was found on the leaf upper faces with signs of sap suction and bronzing. Such injuries caused abnormal development and plant death. The spider mite was identified as Oligonychus yothersi (McGregor) (Acari: Tetranychidae). This is the first record of $\boldsymbol{O}$. yothersi on $\boldsymbol{E}$. grandis seedlings in Brazil.
\end{abstract}

Keywords: Red spider mite, clone seedling, eucalypt.

São escassos os registros de ocorrência de ácaros sobre eucalipto no Brasil. Já foram registradas espécies pertencentes à família Tetranychidae, como Tetranychus urticae (Koch), em Eucalyptus grandis Hill ex Maiden, Oligonychus punicae (Hirst) em Eucalyptus sp. e Oligonychus sp. em Eucalyptus alba Reinw ex Blume e Eucalyptus saligna Smith, além de Oligonychus ilicis (McGregor) em E. grandis, Eucalyptus camaldulensis Dehnh, Eucalyptus pellita F. Muell e Eucalyptus tereticornis Smith (Flechtmann, 1983a). Uma espécie de Eriophyidae descrita como Rhombacus eucalypti Grosh and Chakrabarti foi encontrada em E. tereticornis,
E. grandis e E. camaldulensis (FLECHTMANN e SANTANA, 2001).

Em outubro de 2003, verificou-se infestação, em reboleira, de um ácaro vermelho em mudas clonais de E. grandis mantidas em casas de vegetação com capacidade para 50.000 mudas, no município de Martinho Campos, MG, cuja latitude é de 19³4'20'S, longitude de $45^{\circ} 20^{\prime} 30^{\prime \prime} \mathrm{W}$, e altitude de $745 \mathrm{~m}$. Os ácaros foram constatados na parte superior das folhas e apresentavam coloração geral escura, com o terço anterior do corpo vermelho-amarelado (Figura 1A). As folhas exibiam

\footnotetext{
${ }^{1}$ Recebido em 19.07.2004 e aceito para publicação em 20.04.2005.

${ }^{2}$ Departamento de Biologia Animal/Insetário da Universidade Federal de Viçosa, 36571-000 Viçosa-MG. E-mail: <ffpereira@insecta.ufv.br>; <nanjos@ufv.br>; <ralmado@caf.ind.br>; <luisantonio@insecta.ufv.br>.
} 
sinais de sucção de seiva (Figura 2A), bronzeamento (Figura 1B) e as mais velhas estavam encarquilhadas e caíam facilmente. Cerca de 8 a $10 \%$ das mudas clonais presentes nas casas de vegetação estavam infestadas com o ácaro-vermelho, mas a infestação foi controlada com acaricidas e remoção das mudas mortas e daquelas que apresentavam desenvolvimento anormal (Figura 2B).

Adultos desse ácaro foram capturados, montados em lâminas e enviados ao Dr. Manoel Guedes Corrêa Gondim Júnior, do Departamento de Agronomia/ Fitossanidade da Universidade Federal Rural de Pernambuco, para identificação. O ácaro foi, então, identificado como sendo Oligonychus yothersi (McGREGOR, 1914) (Acari: Tetranychidae).

O. yothersi ocorre desde os Estados Unidos até a Argentina, tendo sido notificado em diversos hospedeiros como abacate, cafeeiro, erva-mate, mangueira e plantas ornamentais (FLECHTMANN, 1979). Os indivíduos dessa espécie apresentam dimorfismo sexual, em que as fêmeas possuem corpos globosos, de aproximadamente $0,5 \mathrm{~mm}$ de largura, colorações laranja no terço anterior do corpo e vermelho-escura no resto. No entanto, os machos são menores, de coloração

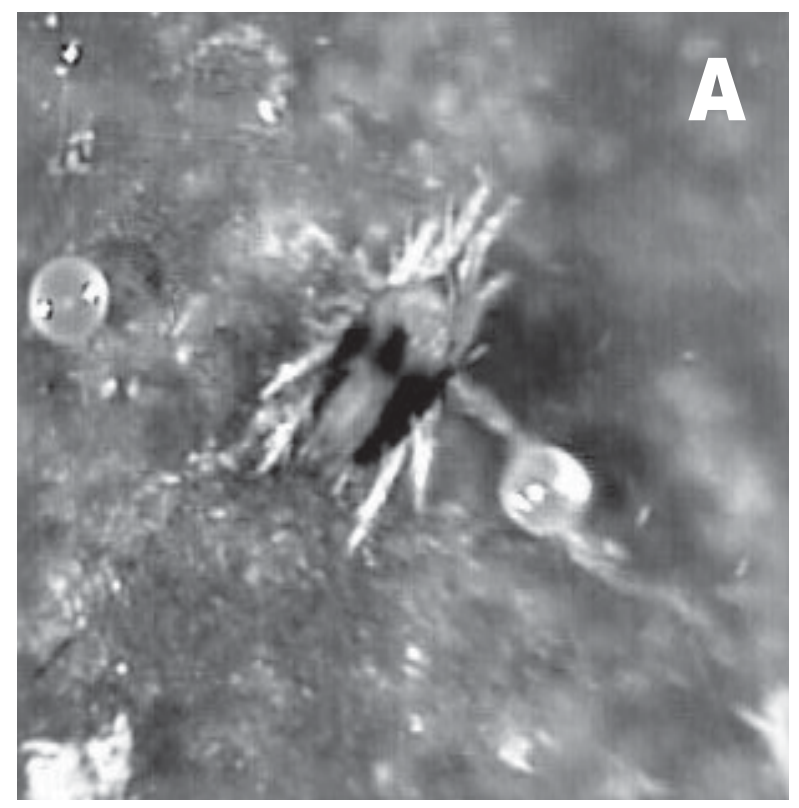

vermelho-amarelada, e possuem pernas maiores do que as das fêmeas. De modo geral, $O$. yothersi caracterizase por produzir teia, onde coloca ovos globosos, vermelhos e providos de pedicelos. A colônia prolifera-se na parte superior das folhas, causando bronzeamento e, quando em altas populações, podem provocar a queda foliar (FLECHTMANN, 1983b).

Uma hipótese que pode justificar a ocorrência de surtos de ácaros fitófagos em viveiros de eucalipto é a redução de inimigos naturais, principalmente os ácaros predadores, fato esse provocado pela aplicação incorreta de inseticidas, fungicidas cúpricos e acaricidas. Condições climáticas favoráveis aos ácaros fitófagos e adubações de nitrogênio inadequadas para a planta também podem favorecer direta e indiretamente a explosão populacional desses ácaros (FLECHTMANN, 1983a). Os danos de $O$. yothersi em $E$. grandis, relatados nesta pesquisa, evidenciam a necessidade de mais estudos na área florestal, visando ao seu manejo integrado. Conhecimentos sobre a ação seletiva ou tóxica dos agrotóxicos usados no controle de pragas do eucalipto em casa de vegetação são importantes na escolha de táticas de manejo que favoreçam a preservação e atuação de artrópodes benéficos.

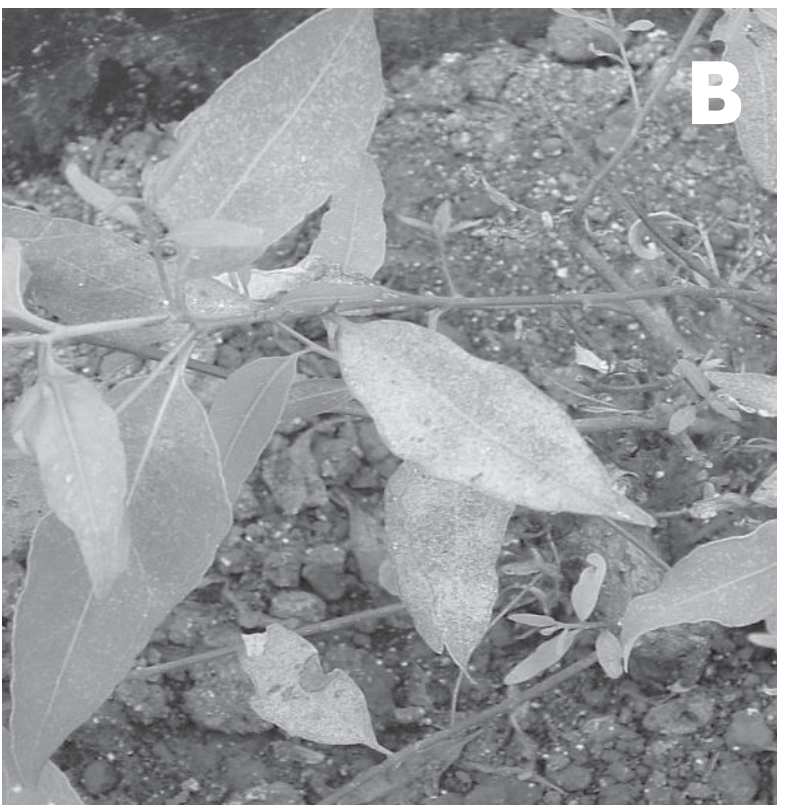

Figura 1 - Fêmea adulta do ácaro-vermelho Oligonychus yothersi (McGregor) (A) e folhas de Eucalyptus grandis com bronzeamento (B).

Figure 1 -Adult female of Oligonychus yothersi (McGregor) (A) and bronzed leaves of Eucalyptus grandis (B). 

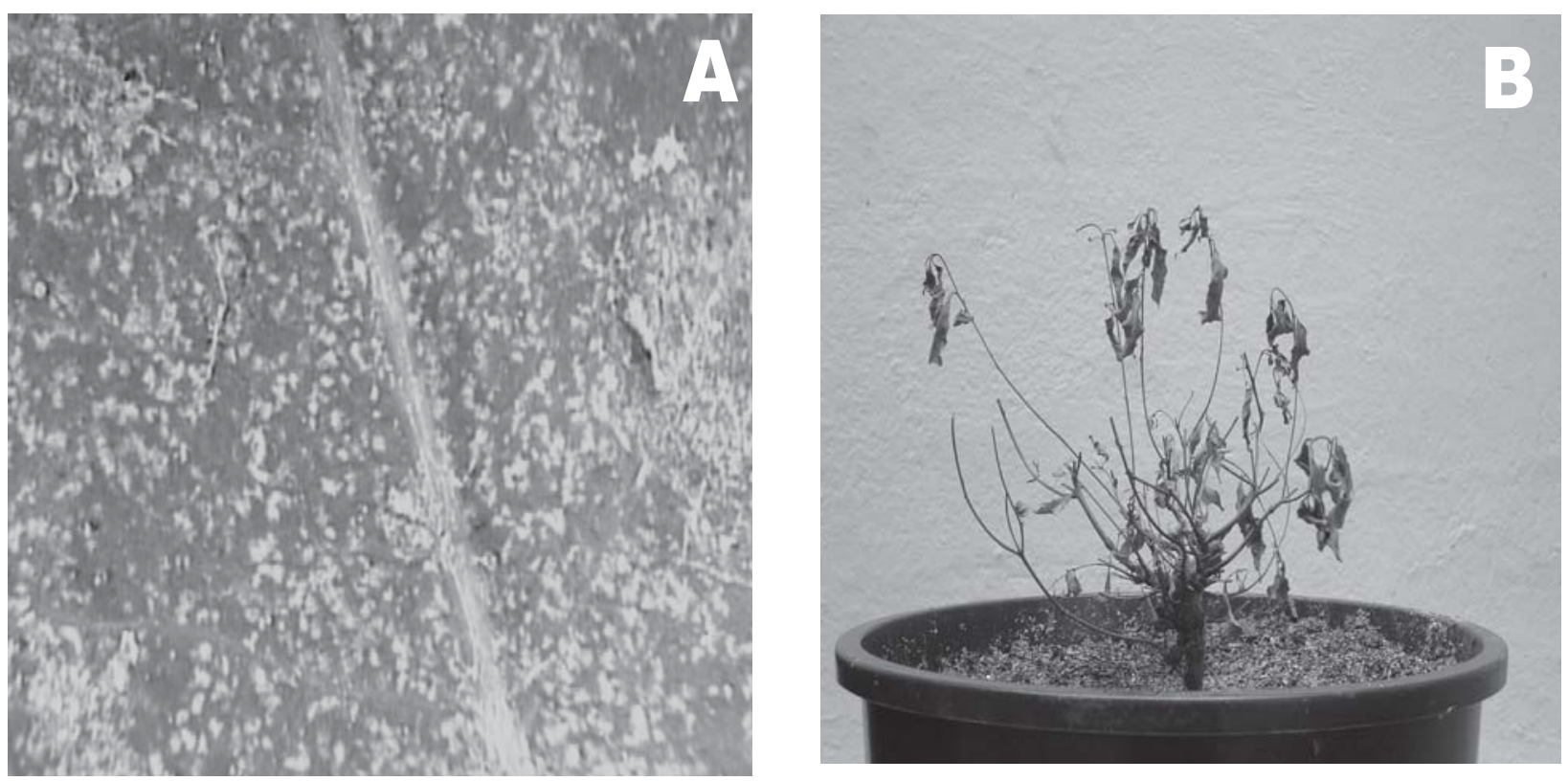

Figura 2 - Folhas com sinais de sucção de seiva (A) e muda clonal de Eucalyptus grandis com queda prematura de folhas (B)

Figure 2 - Leaves with signs of sap suction (A) and clone seedling of Eucalyptus grandis with premature leaf drop.

\section{AGRADECIMENTOS}

Ao Dr. Manoel Guedes Corrêa Gondim Júnior(UFRPE), pela identificação do ácaro; ao Doutorando em Entomologia Walter Santos Evangelista Júnior, por ter colaborado na preparação das lâminas; e à Companhia Agrícola Florestal (CAF), por possibilitar a execução desta pesquisa.

\section{REFERÊNCIAS BIBLIOGRÁFICAS}

FLECHTMANN, C.H.W. Ácaros de importância agrícola. 3. ed. São Paulo: Nobel, 1979. 189p.

FLECHTMANN, C.A.H. Dois ácaros novos para o eucalipto, com uma lista daqueles já assinalados para esta planta. IPEF, v.23, n.1, p.43-46, 1983a.
FLECHTMANN, C.H.W. Ácaros de importância agrícola. 5 ed. São Paulo: Nobel, 1983b. 189p.

FLECHTMANN, C.H.W.; SANTANA, D.L.Q. First record of an Eriophyid mite from Eucalyptus in Brazil, with a complementary description of Rhombacus eucalypti Ghosh and Chakrabarti (Acari: Eriophyidae).

International Journal of Acarology, v.27, n.2, p.123-127, 2001.

SILVA, J.C. Eucalipto: Pesquisa amplia usos Perspectivas do setor florestal brasileiro.

Revista da Madeira, v.13, n.75, p.4-6, 2003. 